\title{
Computers and the Environment: Understanding and Managing their Impacts
}

edited by

Ruediger Kuehr ${ }^{a}$ \& Eric Williams ${ }^{b}$

${ }^{a}$ United Nations University, Zero Emissions Forum, European Focal Point, Hamburg/Germany

b United Nations University, Environment and Sustainable Development, Tokyo/Japan

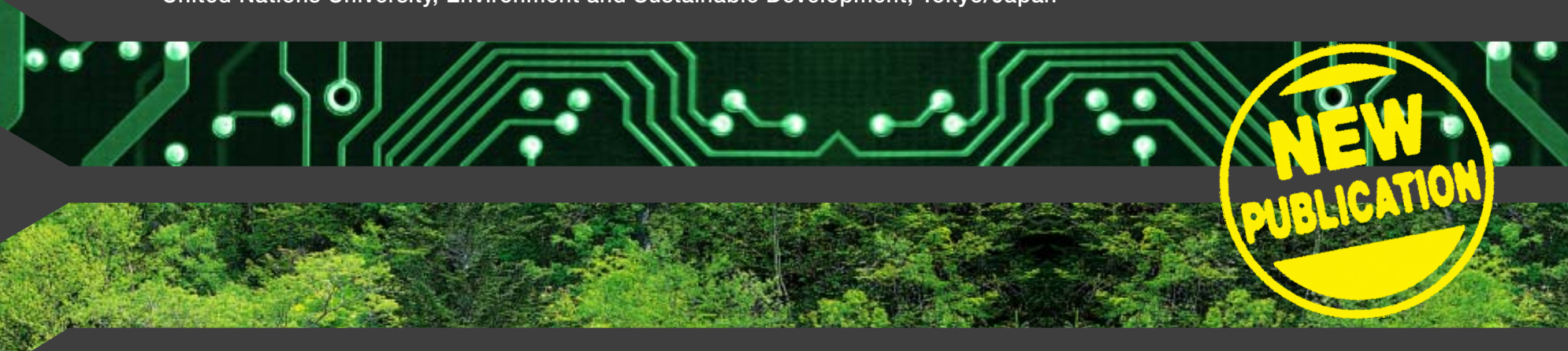

What are the environmental impacts associated with personal computers (PCs)?

How should we manufacture, buy, use and dispose of them so as to reduce these impacts?

Governments and firms are increasingly responding to mitigate some of the problems. In the E.U., Japan, and Taiwan, mountains of waste computers are being dealt with via legislation mandating recycling. Measures are also being taken to reduce the content of lead, mercury and other toxic substances put into computers in the first place. Are these responses enough?

Do we understand enough about the impacts to take appropriate social response?

These questions are taken up in a new edited volume in the Eco-Efficiency in Industry and Science series of Kluwer Academic Publishers: Computers and the Environment, edited by Ruediger Kuehr and Eric Williams. Collecting perspectives from manufacturers, recyclers, environmental scientists and policy analysts, the volume presents a set of analyses on issues important for understanding and planning response to the environmental challenges posed by computers.

Manufacturing computers is materials intensive; the total fossil fuels used to make one desktop computer weigh over 240 kilograms, some 10 times the weight of the computer itself. This is very high compared to many other goods: For an automobile or refrigerator, for example, the weight of fossil fuels used for production is roughly equal to their weights. Also, substantial quantities of chemicals $(22 \mathrm{~kg})$, and water $(1,500 \mathrm{~kg})$ are also used. The environmental impacts associated with using fossil fuels (e.g. climate change), chemicals (e.g. possible health effects on microchip production workers) and water (e.g. scarcity in some areas) are significant and deserve attention.

The environmental benefits and economic costs of recycling computers under the European Union legislation WEEE depend very much on how the system is implemented. Recycling managed by a monopolist concern, whose main interest is meeting simple recycling targets for a fixed fee, could result in an expensive system with relatively small environmental benefit. A multilateral concern aimed at maximizing profit and reuse across the life cycle presents a more promising picture.

Decisions by consumers on how PCs are used and disposed of have an enormous effect on environmental impacts. Extending the usable life is very effective for reducing all types of burdens, but relatively few older PCs are being resold, refurbished or recycled - most are stored in warehouses, basements, or closets and eventually end up in landfills. Awareness building and incentives are needed so that consumers will consider environmental issues when buying, using and finally disposing of a computer. 


\section{TABLE OF CONTENTS}

Preface by Eric Williams and Ruediger Kuehr

1. Computers and the Environment-An Introduction To Understanding and Managing their Impacts Ruediger Kuehr, German T. Velasquez, Eric Williams

2. Information Technology Products and the Environment

H. Scott Matthews and Deanna H. Matthews

3. Environmental Impacts in the Production of Personal Computers Eric Williams

4. How the European Union's WEEE Directive Will Change the Market for Electronic EquipmentTwo Scenarios

Klaus Hieronymi and Axel Schneider

5. IBM's Environmental Management of Product Aspects

Reinhard Höhn and Anne Brinkley

6. Environmental Management at Fujitsu Siemens Computers

Harald Podratzky
7. Energy Consumption and Personal Computers Danielle Cole

8. PCs and Consumers-A Look at Green Demand, Use, and Disposal Mohamed Saied and German T. Velasquez

9. Strategizing the End-of-life Handling of Personal Computers: Resell, Upgrade, Recycle Eric Williams and Yukihiro Sasaki

10. Today's Markets for Used PCs-And Ways to Enhance Them

Eric Williams and Ruediger Kuehr

11. Recycling Personal Computers Stefan Klatt

12. Operations of a Computer Equipment Resource Recovery Facility Joseph Sarkis

13. Managing PCs through Policy: Review and Ways to Extend Lifespan Ruediger Kuehr

Contributors

Index

\section{Bibliographic Details:}

Kuehr, Ruediger \& Eric Williams (eds.): Computers and the Environment:

Understanding and Managing Their Impacts, Kluwer Academic Publishers, EcoEfficiency in Industry and Science Series, Dordrecht/NL, October 2003, 300 pages, Paperbound: ISBN 1-4020-1680-8, EUR 32.00 / USD 35.00 / GBP 22.00 Hardbound: ISBN 1-4020-1679-4, EUR 75.00 / USD 83.00 / GBP 52.00 For more information see http://www.it-environment.org/compenv.html

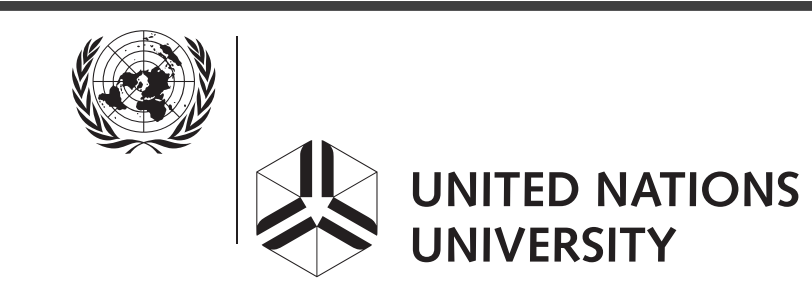

